\title{
Yabancı Dil Olarak Türkçe Öğretiminde Blogların Öğretim Amaçlı Kullanımı Üzerine Öğrenci ve Öğretmen Görüşleri ${ }^{*}$
}

\author{
Dr. Murat Sami Türker \\ Anadolu Üniversitesi Yabancı Diller Yüksekokulu \\ Temel Yabancı Diller Bölümü \\ muratsturker@gmail.com
}

\author{
Prof. Dr. Ayten Genç \\ Hacettepe Üniversitesi Ĕ̆itim Fakültesi \\ Yabancı Diller Eğitimi Bölümü \\ dogu@hacettepe.edu.tr
}

Öz

Dört temel dil becerisinin yanında teknolojiyi kullanma becerisinin de tartışılır olduğu modern eğitim sisteminde, iletişimi ve etkileşimi ön plana çıkaran Web 2.0 araçlarının kullanımı giderek yaygınlaşmaktadır. Bu araştırma, Web 2.0 araçlarından blogların, bir ders dışı öğrenme ortamı olarak tasarlandığında yabancı dil olarak Türkçe öğretimine etkisini araştırmak amacıyla gerçekleştirilmiştir. Tasarım tabanlı yürütülen bu araştırma kapsamında araştırmacı tarafından özgün bir blog sitesi tasarlanmış, hazırlanan öğretim malzemelerinin katılımcılardan alınan geribildirimler ışığında gözden geçirilerek iyileştirilmesi ve geliştirilmesi amaçlanmıştır. Altı haftalık planlanan çalışmanın uygulama süreci yabancı dil olarak Türkçe öğrenen B.2 düzeyinde 24 üniversite öğrencisinin katılımıyla tamamlanmıştır. Uygulama sürecinin ardından, seçkisiz atama yoluyla belirlenen yedi öğrenci ve onlara ders veren iki öğretim elemanıyla yarı yapılandırılmış görüşmeler gerçekleştirilerek uygulamanın kapsamı ve yöntemi, uygulanan etkinlik türleri, blog sitesinin içeriği ve teknik özellikleri değerlendirilmiş, böylece blog kullanımının yabancı dil olarak Türkçe öğretimine etkisi araştırılmıştır. Betimsel analiz yöntemleri kullanılarak ulaşılan sonuçlar, öğrenciler için yeni bir öğrenme biçimi olan blogların eğlenceli ve etkileşimli bir öğrenme ortamı hazırlayarak öğrenmeye karşı motivasyonu artırdığı yönündedir. Ayrıca, geleneksel öğrenme yöntemleri ile karşılaştırıldığında, güncel ve ilgi çekici içeriğe sahip olan blogların derse olan katılımı ve iletişimi arttığı yönündeki sonuçlar, blogların içeriğinin diğer beceri düzeylerini de kapsayacak şekilde geliştirilmesi ve sınıf içi uygulamalarının da araştırılması ihtiyacını ortaya koymuştur.

Anahtar Kelimeler: Yabancılara Türkçe öğretimi, Web 2.0 araçları, blog, sınıf dışı etkileşim, tasarım tabanlı araştırma.

\footnotetext{
*Bu makale, Prof. Dr. Ayten Genç danışmanlığında tamamlanan Yabancı Dil Olarak Türkçe Öğretiminde Blog Kullanımının Okuma Becerisine Etkisi başlıklı Doktora tezinden üretilmiştir. 


\title{
Students' and Teachers' Views on Instructional Use of Blogs in Teaching Turkish as a Foreign Language
}

\begin{abstract}
As it promotes communication and interaction, the use of Web 2.0 tools has gradually increased in modern education system where technological capability is discussed as one of the basic language skills. This study has been conducted to investigate the effects of blogs on teaching Turkish as a foreign language, when designed as an out-of-class learning environment. In the light of the principles of blended learning, a blog page was created by the researcher and it was aimed to revise and improve the material based on the participants' feedback. The implementation process of the study lasted six weeks and was conducted with the participation of 24 university students who are learning Turkish as a foreign language in B2 proficiency level. In order to investigate the effects of blog use on teaching Turkish as a foreign language, semi-structured interviews were held with seven students and two instructors, who were randomly selected after the implementation process, and they were asked to evaluate the scope and method of the study, activity types and the content and technical features of the blog site. The qualitative results of the study showed that blogs, as a new learning model for students, improve motivation for learning by preparing an enjoyable and interactive learning environment. When compared with traditional learning methods, the results also showed that blogs have up-to-date and interesting content, and therefore they increase participation and communication among students. These findings suggest the need for further research on developing blog content considering other proficiency levels and exploring the implementation of blogs in class environments.
\end{abstract}

Keywords: Teaching Turkish to foreigners, Web 2.0 tools, blog, out-of-class interaction, design based research. "This article is part of the PhD thesis titled "The Effectiveness of Blog Use on the Reading Skills in Teaching Turkish
as a Foreign Language", which was written by Murat Sami Türker under the supervision of Ayten GENÇ. 


\section{GİRIS}

Sınırların giderek ortadan kalktığı günümüz dünyasında en çok tartışılan kavramlardan biri olan çok dillilik, insanların yaşamında ihtiyaçlar listesinin en üst sıralarında yerini almıştır. Söz konusu bu ihtiyacı karşılayabilmek amacıyla, son yıllarda bu doğrultuda yürütülen çalışmalar oldukça hız kazanmıştır. Çok dilliliğe büyük önem veren Avrupa Konseyi üye ülkeleri de yabancı dil öğretim programlarını vatandaşlarının iki ya da daha fazla dil öğrenmelerine olanak sağlayacak şekilde tasarlamaktadırlar. Bu arayış, yabancı dillerin öğretiminde bugüne kadar birçok farklı yöntem, yaklaşım ve tekniklerin geliştirilmesini de beraberinde getirmektedir. Bu farklılıkların temelinde kurumların yabancı dil öğretimi amaç ve hedefleri, öğrencilerden beklentileri, ulaşılması hedeflenen beceri ve dil düzeyleri yer almaktadır. Uygulamalar ne derece farklı olursa olsun, bugün yabancı dillerin öğretiminde öğrenci merkezli eğitim tartışılmayan temel kavramlardandır.

Günümüz koşulları göz önüne alındığında, öğrenciyi merkeze alan bir eğitim anlayışında teknoloji göz ardı edilerek bir yöntem geliştirilmesi mümkün görünmemektedir. İnsanoğlunun yaşamında ulaşımdan haberleşmeye, iş hayatından alışverişe kadar birçok alanda köklü değişimlere neden olan teknolojik gelişmeler eğitim alanında da karşıllık bulmuş ve buna bağlı olarak eğitim teknolojileri kavramı doğmuştur. Bilim ve teknoloji alanında yaşanan gelişmeleri yakından takip eden ve Dijital yerliler olarak adlandırılan yeni nesil öğrencilerin teknolojiyi kullanma konusundaki yetenekleri ve sahip oldukları teknolojik olanaklar, gerek sınıf içinde gerekse sınıf dışında öğretme ve öğrenme eylemlerini etkilemektedir. Eğitimciler artık teknolojiyle zenginleştirilmiş öğretim malzemeleri tasarlamak ve programlar geliştirmek durumundadır. Dünyaya açılan kapının anahtarı olan yabancı dil öğretimi de, teknoloji desteğine en çok ihtiyaç duyulan alanlardan biri olmuş ve teknoloji destekli yabancı dil öğretim modelleri, malzemeleri ve ortamları geliştirilmeye başlanmıştır.

Geleneksel eğitim anlayışıyla yabancı dil eğitimi veren kurumlar artık bilgisayar laboratuvarları, akıllı tahtalar, yansıtma cihazları ve sanal öğrenme ortamları gibi teknoloji desteğini okul sınırları içerisinde öğrencilerine sunmaktadır. Ancak, öğrenilenleri sınıf dışında pekiştirmeye ve uygulamaya olanak sağlayan öğrenme ortamlarının henüz yeterli olduğu söylenemez. Buna bağlı olarak, günümüzde çoklu ortamlarla zenginleştirilmiş teknoloji destekli öğretim malzemeleri geliştirme çalışmaları sürdürülmektedir. Sydorenko, Myers ve Nakhimovsky'a (2008: 186) göre, bu tür öğretim malzemeleri, bireylere kendi öğrenme deneyimlerini kontrol etme olanağı sunmakta, ayrıca zaman ve mekân kısıtlaması olmadan herkesin erişimine açık olup farklı öğrenme stillerine sahip bireylerin ihtiyaçlarına karşıllı vermektedir. Teknoloji destekli öğretim malzemeleri özgün kaynaklara ulaşım olanağ 1 sağlamakla kalmayıp stresten uzak öğrenme ortamı sunarak öğrenmeyi kolaylaştırmakta ve çok sayıda bireye aynı anda iletişim olanağı sağlamaktadır.

Öte yandan, teknoloji tabanlı öğrenme ortamlarının öğretmenlere sağladığı birçok avantaj bulunmaktadır. Bush'a (1997: 297) göre, teknolojiden yararlanarak işitsel ve görsel özgün öğrenme malzemeleri ile daha gerçekçi öğrenme ortamları oluşturabilen öğretmenler de avantajlıdır. Bu sayede etkili ve işbirlikli bir öğrenme ortamı hazırlayarak öğrencilerin derse olan ilgilerini artırırlar. Öğrencilerin bireysel ihtiyaçlarına ve öğrenme stillerine göre ders planı ve ders içeriği oluşturmakla kalmayıp onların gelişimlerini de yakından takip edebilirler.

Aslında bugüne kadar yapılan birçok çalışmada öğrenmenin ön koşulu niteliğinde olan motivasyon ile teknoloji arasında güçlü bir ilişkinin bulunduğu anlaşılmıştır (Kartal 
2001; İlter 2009; Altun 2015). Teknolojinin eğitimle buluşturulmasıyla birlikte şimdiye dek bilinenlerin, örneğin öğrenci ve öğretmen rollerinin değişmesi söz konusu olmuştur. Öğretmenlerin bilgiyi aktarıcı, öğrencilerin ise pasif alıcı konumunda olduğu geleneksel uygulamaların aksine, öğretmenler artık iletişimin bir tarafı olarak öğrenmeyi kolaylaştıran, öğrenciler ise öğrenme sürecine etkin katılan, sorumluluk alan, öğretmenle ve diğer öğrenenlerle etkileşim halinde bilgiyi yorumlayan bireyler konumundadır (White 2003: 65, 68).

Eğitimde teknoloji kullanımı yeni bir olgu değildir. İlk örneklerine 1960'lı yıllarda mikrobilgisayarların eğitim ortamlarına girmesiyle rastlanan eğitim teknolojileri (HopeTaylor vd. 1984: 6), sonraları insan hayatında yeni bir çağın başlangıcı olarak kabul edilen kişisel bilgisayarın icadı ve internetin de yaygınlaşmasıyla yeni bir boyut kazanmıştır. Ĕgitimin her kademesinde ve her alanında yadsınamaz öneme sahip olan bilgisayarlar, yabancı dil öğretiminde de yeni yaklaşımların zeminini hazırlamıştır.

İletişimsel yaklaşımla birlikte özgün malzeme kullanımı, dilin toplumsal boyutu, iletişim ve etkileşim gibi kavramlar yabancı dil öğretiminde yeni araştırmalara konu olmuştur (Larsen-Freeman 2000: 128, 132). Bugün, eğitimciler dili idealize edilmiş öğrenme ortamlarından çıkararak gerçek dile yakın öğretim malzemeleri ve program geliştirme arayışı içerisine girmişlerdir (Larsen-Freeman 2000: 132-133). İletişimsel yaklaşımın temel prensiplerinden olan dille birlikte kültürü de aktarabilmek ve dili sosyal yaşamın dinamikleriyle ilişkilendirebilmek adına resimler, yansıtıcılar, teypler ve televizyonlar bugün hala birçok yabancı dil sınıfında kullanılmaktadır.

Sınıf içinde ve dışında etkileşimli, işbirlikli ve anlamlı öğrenmeler gerçekleştirebilme çabası, eğitimcileri öğrenen merkezli yeni yöntem ve uygulamalar geliştirmeye yöneltmiştir. Teknolojiyi yaşamlarının her anına uyarlama konusunda son derece yetenekli olan dijital yerlilerin pedagojik ihtiyaçlarına çözüm bulma arayışı, bugün birçok teknoloji altyapısının kaynağı olan bilgisayar desteğinin eğitimde kullanılmasını zorunlu kılmaktadır. Yabancı dil öğretimi alanında bilgisayarların sunduğu olanaklar ise, internetin de yaygınlaşmasıyla süratle geliştirilmektedir. Bilgisayar destekli dil öğretim uygulamalarının ilk örnekleri bilgisayar laboratuvarlarında ve öğretmen kontrolünde gerçekleştirilen etkinliklerle sınırlı iken, bugün öğrenciler dizüstü bilgisayarlar, tablet bilgisayarlar, avuç içi bilgisayarlar, akıllı telefonlar gibi cihazlarla belirli bir mekân ya da zaman sınırı olmaksızın öğrenme sürecine etkin katılabilmektedirler.

Yabancı dil öğretiminde bilgisayar kullanımının öğretmen ve öğrenciler açısından avantajlı olduğu görülmektedir. Etkileşimli öğrenme ortamları sunarak öğrenmeyi ilginç kılması (Odabaşı 1997: 19; Egbert 2005: 6; Schwienhorst 2008: 59), çoklu ortamlarla zenginleştirilmiş öğretim malzemeleri hazırlama ve etkin kullanma olanağı sağlaması (Ahmad-Corbett vd. 1985: 4), bilgisayar kullanımı bireylere kendi öğrenme ortamlarının tasarlanmasında aktif rol alarak öğrenen özerkliğinin gelişimine yardımcı olması (Egbert 2005: 7-8; Schwienhorst 2008: 59), çok sayıda özgün öğrenme malzemesine zaman ve mekân kısıtlaması olmadan bireysel erişim kolaylığı sağlaması (Ahmad-Corbett vd. 1985: 4; Szendeffy 2005: 4), stressiz ve kaygı düzeyi düşük bir ortamda bireylere risk alma ve hedef dili kullanma olanağı sunması (Egbert 2005: 7), yanlış yazılan sözcükleri anında düzelterek sözcüklerin doğru öğrenilmesini ve pekiştirilmesini sağlaması (Demirel 1987: 75; Sarıçoban 2006: 40) gibi açılardan öğrencilere yarar sağlamaktadır.

Öğretmen açısından ise, bilgisayarlar ders ve etkinlik içeriklerini öğrencilerin yeterlik düzeyine göre uyarlayabilme imkanı sağlar (Ahmad-Corbett vd. 1985: 5; Egbert 2005: 6, 8). 
Aynı zamanda, dersi tekrar etme, ödev düzeltme, dönüt verme gibi görevleri yerine getirmesi ve öğrencilerle bireysel ilgilenebilme olanağı sunması (Sarıçoban 2006: 40; Demirel 2009: 181) nedeniyle bilgisayarlar öğretmenlere büyük kolaylıklar sağlamaktadır.

Bunların yanı sıra, bilgisayarların aklı, zekâsı ya da öğretme ve öğrenme yeteneği olmayan; ancak verilen komutaları yerine getirebilen araçlar olduğu unutulmamalıdır. Başarıyı getiren sadece bilgisayarlar değil, aynı zamanda öğretmenin bilgisayar kullanma yeteneği ve zekâsıdır (Ahmad-Corbett vd. 1985: 2, 3, 9). Öğretmen, öğrenme çıktılarını ve hedef kitlenin özelliklerini değerlendirerek bilgisayar destekli etkinlikler tasarlayabilmelidir. $\mathrm{Bu}$ sebeple, öğretmen adaylarının bilgisayarlar ve pedagojik uygulamaları konularında iyi yetişmiş bireyler olmaları bugünün eğitim sisteminde büyük önem taşımaktadır (ŞahinAkçay 2011: 910).

Yabancı dil öğretiminde bilgisayar kullanımı internetin mobil cihazlarda bile kullanılabilir hale gelmesiyle farklı bir boyut kazanmıştır. Bilgisayar destekli dil öğrenme uygulamaları önceleri eğitici oyunlar, testler ve ezber etkinlikleri ile sinırlı iken, internet sayesinde insanlar diğer dil öğrenenlerle ve dilin doğal konuşucularıla yer ve zaman sınırlaması olmadan gerçek iletişim kurabilme imkânı elde etmişlerdir (Kern-Warschauer 2000: 8, 11). Dil öğrenenler ile dilin doğal konuşucuları arasında gerçekleşen bu eşzamanlı ve eşzamansız gerçek iletişim ortamları da yabancı dil öğretiminin en önemli unsurlarından olan özgün dil kullanımını desteklemektedir (Sharma-Barrett 2007: 98).

İnternet, bireylere yetenekleri ve ilgi alanlarına göre öğrenme ortamını düzenleme imkânı sunar (Şahan 2007: 236), basılı malzemeleri güncel ve zengin içeriklerle destekleyerek öğrenmeye karşı ilgiyi arttırır (Sharma-Barrett 2007: 10, 11). İnternet, öğrencilere sağladığ1 iletişim ve araştırma olanağının yanında, Web2.0 araçları denilen çoklu ortam uygulamaları sayesinde etkileşimli öğrenme ortamları hazırlar. İletişimi ve paylaşımı arttırarak sosyal öğrenmenin önünü açan Web 2.0 araçları, kendilerini ifade edebilme ve fikirlerini başkalarıyla paylaşma konusunda öğrencilere yardımcı olur (Mondahl-Razmerita 2014: 342). Öğrencilere kendi dijital öğrenme malzemelerini tasarlama fırsatı sunması da, öğrenme sürecine etkin katılımı arttırır (Bates 2011: 21). Öğretmenin bilgiyi aktaran ve öğrenmeyi denetleyen rolünü üstlendiği geleneksel öğrenme ortamlarının aksine, Web 2.0 araçlarıyla tasarlanmış bir öğrenme ortamında öğretmen baskısını hissetmeyen öğrenciler özgürce davranabilmekte ve öğrenme sürecinde sorumluluk alabilmektedirler. Bu sayede, bir konu alanında bilgi edinmek üzere bir araya gelmiş insanların işbirlikli öğrenmelerinin önü açılarak öğrenme topluklarının oluşumuna zemin hazırlanır (Solomon-Schrum, 2010: 4, 8).

Yaşam boyu öğrenme becerilerinden söz edilen günümüz dünyasında sadece sinıf içinde değil, sınıf dışında da öğrenme ortamlarının oluşturulmasının çok sayıda yararlar sağlayacağı düşünülmektedir. Sınıf dışında öğrencilerin ihtiyaç duydukları etkileşimli dil öğrenme ortamları, sahip oldukları teknolojik araçlar da göz önünde bulundurulduğunda "ağ günlükleri” olarak da bilinen bloglar olarak karşımıza çıkmaktadır.

Bloglar, kod yazma gibi teknik bilgi ve beceri gerektirmeden, insanlara fikirlerini çevrimiçi ortamlarda ifade edebilme ve dünyanın her yerinden milyonlarca insanla paylaşabilme olanağı sunar (Šabanović 2015: 11; Al-Qallaf-Al-Mutairi 2016: 523). Bu yönüyle bloglar, aslında yazmaya ya da okumaya ilgili kişiler için ücretsiz, çevrimiçi bir yayınevi niteliği taşımaktadır (Ward 2004: 2). Sıradan bir günlükle benzer özellikler taşımasına karşın bloğu günlükten ayıran en belirgin fark, blogda yazılan yazıların yoruma açık olmasıdır. Bloglar, bu çok yazarlı yapısı ile bir konuyu farklı bakış açısından değerlendirme olanağı sunmaktadır (Ward 2004: 3). Ses, görüntü ve video gibi çoklu ortam nesnelerinin 
paylaşımına izin vermesi, içeriğin sürekli güncellenerek yeniden eskiye doğru sıralanması ve diğer blog sayfalarına ve internet sitelerine köprü bağlantılara sahip olması tüm blogların ortak özelliği olarak karşımıza çıkmaktadır (Sharma-Barrett 2007: 24, 115, 120; Baron 2008: 110; Yüksel 2014: 23-24; Šabanović 2015: 11).

Blogların yabancı dil öğretiminde kullanımı ile ilgili alanyazında yürütülmüş ve devam etmekte olan çalışmalar mevcuttur. Bu çalışmalarda, İngilizce başta olmak üzere çeşitli dillerin yabancı dil olarak öğretiminde blog etkisi araştırılmıştır (Aydan 2014; Blackstone-Spiri vd. 2007; Izquierdo-Reyes 2009; Noytim 2010; Rashtchi-Hajihassani 2010; Zarei-Al-Shboul 2013; Zeqiri 2013; Nicolaou-Constantinou 2014; Temir 2015). Ancak, Türkçenin yabancı dil olarak öğretiminde blogların etkisini araştıran çalışmalar sayıca sınırlı olmakla birlikte, okuma becerisi bağlamında blog etkisine yönelik kapsamlı bir çalışma henüz yapılmamıştır. Bu çalışma, yabancı dil olarak Türkçe öğretiminde blog kullanımına yönelik öğrenci ve öğretmenlerin görüşlerini araştırmaktadır. Bu amaçla, araştırmacı tarafından özgün olarak bir blog sitesi tasarlanarak uygulama değerlendirilmiştir.

\section{AMAÇ}

Çok dilliliğin bir yaşam standardı haline geldiği günümüz dünyasında, yabancı dil öğretim yöntemleri ve programları geliştirirken göz ardı edilemeyecek en önemli etkenlerden biri de hedef kitlenin ihtiyaçları ve ilgi alanlarıdır. Önceki nesillere göre teknolojiyi kullanma konusunda üstün yetenekli olan yeni nesil öğrencilerin iletişimden eğlenceye, sosyal yaşamdan haberleşmeye kadar yaşamlarını dijitalleştirme eğilimleri yabancı dil öğretiminde de etkilerini göstermektedir. Hem sınıf içinde hem de sınıf dışında gerçek dil kullanımına en yakın örnekleri sunabilmek, işbirlikli öğrenme ortamları tasarlamak, iletişimi ve etkileşimi ön plana çıararak öğrenmeyi anlamlandırmak gibi temel gereksinimlerin karşılanmasında, hiç şüphe yok ki teknoloji çok önemli bir yere sahiptir. Bu çalışma kapsamında, araştırmacı tarafından özgün olarak bir blog sitesi tasarlanmış ve söz konusu ihtiyaçların karşılanması amacıyla hazırlanan içerik sınıf bir dışı etkinlik olarak uygulanmıştır. Uygulama sürecinin sonunda, öğrencilerin ve öğretim elemanlarının blogların dil öğretiminde kullanılması ile ilgili görüş ve önerileri alınarak çalışmanın amaçları doğrultusunda değerlendirilmiştir.

\section{YÖNTEM}

Araştırmacı tarafından kurgulanan blog destekli öğretim malzemelerinin Türkçenin yabancı dil olarak öğretimi sürecine etkisinin araştırıldığı bu çalışma, karma öğrenme modelinin ilkelerine dayanarak tasarlanmıştır. Tasarım tabanlı bir araştırma olan çalışmada, blog destekli öğretim malzemelerinin öğrenci ve öğretmenlerin görüş ve önerileri doğrultusunda gözden geçirilerek iyileştirilmesi ve geliştirilmesi amaçlanmıştır. Bu amaçla, altı haftalık planlanan çalışmanın uygulama sürecinde, her hafta uygulanan etkinliklerin ardından araştırmacı tarafından geliştirilen bir tasarım geliştirme anketi ile öğrencilerden geribildirimler alınmıştır. Böylelikle, etkinliklerin içeriği, düzeye uygunluğu ve sayfanın teknik özellikleri geribildirimler doğrultusunda değerlendirilmiş ve sonraki etkinliklerin içeriği ve uygulama biçimi tasarlanmıştır. Uygulama sonrası süreçte, öğrenci ve öğretim elemanlarıyla görüşmeler gerçekleştirilerek uygulamanın kapsamı ve yöntemi, uygulanan etkinlik türleri, blog sitesinin içeriği ve teknik özellikleri değerlendirilerek blog uygulamasının öğrenme sürecine etkisi araştırılmıştır. Elde edilen tüm bu verilerle yabancı dil olarak Türkçe öğretimi alanında özgün, ilgi çekici ve uygulanabilirliği denenmiş blog 
destekli bir öğrenme ortamı tasarlanmıştır. Bu çalışma kapsamında aşağıdaki araştırma sorularına yanıt aranmıştır.

1. Öğrencilerin blogların dil öğretiminde kullanılmasına yönelik görüşleri ve uygulamaya yönelik önerileri nelerdir?

2. Öğretmenlerin blogların dil öğretiminde kullanılmasına yönelik görüşleri ve uygulamaya yönelik önerileri nelerdir?

Çalışmanın verileri, araştırmacı tarafından özgün olarak hazırlanan görüşme formları kullanılarak öğrenciler ve öğretim elemanları ile yüz yüze yapılan görüşmelerden elde edilmiştir. Türkçenin yabancı dil olarak öğretiminde blog kullanımına yönelik öğrenci ve öğretim elemanların görüşlerinin araştırıldığı bu nitel çalışma, yapısı gereği yarı deneysel bir çalışmadır.

\section{1. Çalışma Grubu}

Çalışmanın uygulama aşaması, OGÜ TÖMER ${ }^{1}$ de yabancı dil olarak Türkçe öğrenen ve 2016-2017 akademik yılı bahar döneminde OGÜ TÖMER tarafından yapılan seviye belirleme sınavı sonuçlarına göre B2 düzeyine devam eden 24 öğrencinin katılımıyla gerçekleştirilmiştir ${ }^{2}$. Çalışmanın veri toplama aşaması ise, altı haftalık uygulama sürecinin ardından seçkisiz atama yoluyla belirlenen yedi öğrenci ve onlara ders veren iki öğretim elemanın katılımıyla gerçekleştirilmiştir. Uygulamanın ders dışı bir etkinlik olarak tasarlanması sebebiyle, sınıf dışında bilgisayar ve mobil cihazlar kullanılarak kendi öğrenmelerinde sorumluluk alabilecek ve blog sitesi dışında farklı kaynaklara başvurmadan etkinlikleri tamamlayabilecek nitelikteki bağımsız kullanıcılar olan Türkçe B2 düzeyindeki öğrenciler çalışma için uygun görülmüştür.

\subsection{Veri Toplama Araçları}

Tasarım tabanlı nitel bir araştırma olan bu çalışmanın uygulama aşamasında kullanılmak üzere araştırmacı tarafından bir blog sitesi tasarlanmıştır. Çalışmanın verileri ise, yine araştırmacı tarafından özgün olarak hazırlanan öğrenci ve öğretim elemanı görüşme formlarından elde edilmiştir ${ }^{3}$.

3.2.1. Blog tasarımı: Araştırmacı tarafından özgün olarak tasarlanan blog için kullanım kolaylığı ve mobil cihazlara uyumluluğu sebebiyle Wordpress altyapısı tercih edilmiş ve "Neredeysem Türkçe Orada" ${ }^{4}$ adıyla bloğa erişim sağlanmıştır. Blogda yapılan paylaşımlardan anında haberdar olmaları için öğrencilere kısa mesaj ve e-posta yoluyla bildirimler gönderilmiştir. Böylelikle, öğrenciler bir ders dışı öğrenme ortamı olarak tasarlanan uygulamaya katılmaları konusunda teşvik edilmişlerdir.

Sekiz bölümden oluşan bloğun birinci bölümünde, çalışmanın amacı ve uygulama süreci ile ilgili açıklamalara yer verilmiştir. Çalışma kapsamında, Diller için Avrupa Ortak Öneriler Çerçevesinde (Telc 2013) belirtilen B2 düzeyi okuma becerisi kazanımları esas alınarak altı farklı okuma stratejisinin öğretimi hedeflenmiş, belirlenen okuma stratejilerinin öğretimi ikinci bölüm olan Konu Anlatımı sayfasında gerçekleştirilmiştir. Üçüncü bölümde, B2 düzeyine uyarlanmış gazete haber metinleri üzerinden okuma stratejilerine yönelik hazırlanan etkinliklere yer verilmiştir. Blogda paylaşılan haber metinlerinin düzeye ve hedef

\footnotetext{
${ }^{1}$ Osmangazi Üniversitesi, Türkçe Öğretimi Uygulama ve Araştırma Merkezi

${ }^{2}$ Çalışmanın TÖMER'de uygulayabilmesi için 23.05.2017 tarihinde Osmangazi Üniversitesi Rektörlügünden gerekli izinler alınmıştır.

${ }^{3}$ Çalışmada kullanılacak veri toplama araçları için gerekli olan Etik Kurul İzni 06.04.2017 tarihinde Hacettepe Üniversitesinden alınmıştır.

${ }^{4} \mathrm{https}: / /$ neredeysemturkceorada.wordpress.com
}

SEFAD, 2018 (39): 251-266 
kazanımlara uygunluğunun belirlenebilmesi amacıyla yabancılara Türkçe öğreten dört okutman ve B2 düzeyindeki on öğrencinin görüşleri alınarak uygulama öncesinde metinler gözden geçirilmiştir. Metinlerde geçen anlaşılması güç terimlerle ilgili bir sözlükçe, etkileşimi ön plana çıkaran tartışma alanı, haberle ilgili farklı sitelere bağlantı adresleri ve tasarım geliştirme anketi de bu bölümde yer almaktadır.

Bunları Biliyor musunuz? başlıklı dördüncü bölümde fazladan okuma etkinliği yapmak isteyen öğrencilerin ilgisini çekebilecek nitelikte konu ve içeriğe sahip gazete haber metinleri paylaşılmıştır. Bloğun Sesli Kütüphane adlı beşinci bölümünde okumayı eğlenceli hale getirebilmek amacıyla Türk edebiyatından seslendirilmiş öyküler paylaşılmıştır. Uzunlukları yaklaşı 12 ile 16 dakika civarında olan öyküler bilgisayar ve mobil cihazlarda okunabilir ve dinlenebilir formatta düzenlenmiştir. Bu sayede, öğrencilerin zaman ve mekândan bağımsız olarak öyküleri okuma ve dinleme olanağı bulabilmeleri sağlanmıştır.

Öğrencilerin ihtiyaç halinde başvurabilecekleri çevrimiçi sözlük sitelerine ait bağlantı adresleri alt menüler halinde altıncı bölüm olan Sözlükler sayfasına eklenmiştir. TürkçeTürkçe, Türkçe-İngilizce, Türkçe-Almanca, Türkçe-Fransızca, Türkçe-İtalyanca, Türkçeİspanyolca, Türkçe-Arapça, Türkçe-Rusça, Türkçe-Arnavutça ve Türkçe-Sırpça olmak üzere 12 dilde hazırlanan sözlüklere tıklandığında, farklı açılır pencereden sözlüğün orijinal internet sayfasına yönlendirilerek öğrencilerin blogdan çıkış yapmadan çalışmaya devam edebilmeleri sağlanmıştır.

Mağaza sayfası, yabancılara Türkçe öğretmek amacıyla hazırlanmış bilgisayar ve akıllı telefon uygulamalarının paylaşıldığı bölümdür. Günlük yaşamda ihtiyaç duyulan konuşma kalıpları ve sözcük çalışmaları, dinleme ve yazma alıştırmaları, sesletim ve çeviri gibi etkinliklerin yer aldığı uygulamalar bilgisayarlar ve mobil cihazlar üzerinden ücretsiz kullanılabilen uygulamalardır. Son bölümde, araştırmacı yapılan paylaşımlarla ilgili bilgilendirmeleri ve çalışmaya yön verecek duyuruları paylaşmıştır.

Blog sitesi, Bilgisayar ve Öğretim Teknolojileri alanında uzman iki akademisyenin görüşleri alınarak teknik açıdan değerlendirilmiş, ayrıca yabancılara Türkçe öğreten iki okutmana danışılarak içerikle ilgili gerekli düzenlemeler tamamlanmış ve blog çalışma için uygun hale getirilmiştir. Tasarlanan blog sitesinin ana sayfa ekran görüntüsü Resim 1'de gösterilmiştir.

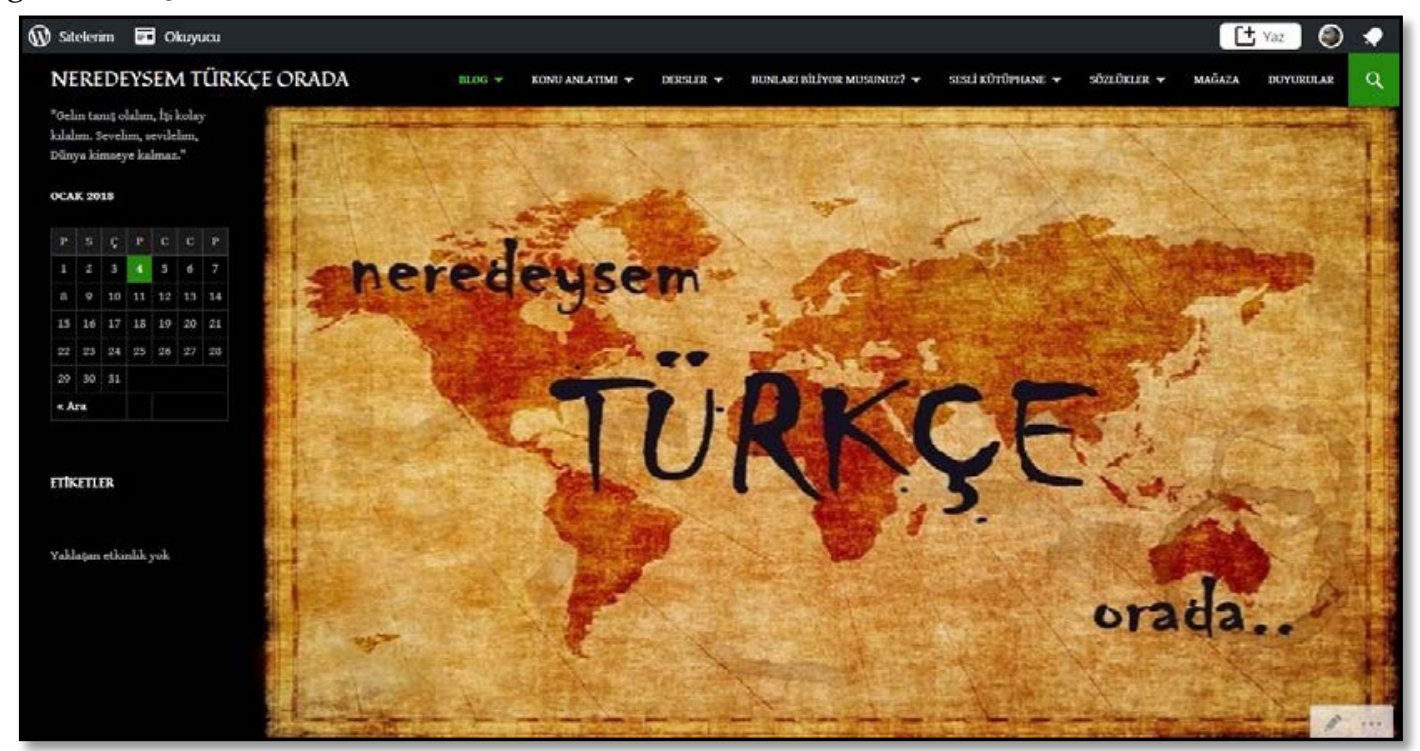

Resim 1: Blog Sitesi Ana Ekran Görüntüsü 
3.2.2. Tasarım geliştirme soruları: Uygulama sürecinin altı hafta olarak belirlendiği bu çalışma, tasarım tabanlı araştırma yönteminin ilkelerine bağlı kalınarak yürütülmüştür. Haftalık sunulan ders dişı etkinliklerin ardından, her hafta blogda bir Tasarım Geliştirme Anketi uygulanarak yapılan etkinliklerle ilgili öğrencilerin görüşlerine başvurulmuştur. Blog tasarımı ve içeriği, etkinliklerin düzeye uygunluğu ve uygulama süresi gibi sorulardan oluşan Tasarım Geliştirme Anketinden elde edilen geri bildirimler doğrultusunda, blog teknik özellikler ve içerik bağlamında gözden geçirilerek yeniden tasarlanmıştır. Çalışma sonunda, katılımcılarla işbirliği yapılarak onların ilgi ve ihtiyaçlarına göre hazırlanmış, etkililiği ve uygulanabilirliği denenmiş blog tabanlı bir öğrenme ortamı alana kazandırılmıştır.

3.2.3. Görüşme formları: Uygulama sonunda, yarı yapılandırılmış yüz yüze görüşmelerle öğrenci ve öğretim elemanlarının blog uygulamasına yönelik görüş ve önerileri alınmıştır. Bu amaçla, araştırmacı tarafından ilgili alan yazın incelenerek öğrenci ve öğretmen görüşme formları hazırlanmıştır. Uygulanan blog etkinliklerinin okuma başarısına etkisi, uygulamada karşılaşılan sorunlar, blogların öğrenciler ve öğretmenler açısından avantajları ve dezavantajları, geleneksel öğrenme ve blog destekli öğrenme arasındaki farklar gibi konuların ele alındığı görüşme formları uzman görüşleri dikkate alınarak gözden geçirilmiş ve soruların anlaşılırlığının test edilmesi amacıyla B2 düzeyindeki dört öğrenci ve iki okutmanla bir pilot çalışma yapılmıştır. Pilot çalışmayla uygulamaya hazır hale getirilen formlar, çalışmanın katılımcılarına uygulanmıştır.

\subsection{Uygulama Süreci}

Konu Anlatımı sayfasında, haftanın ilk günü bir okuma stratejisi ile ilgili açıklamalar paylaşılmış, gazete haber metinleri üzerinden hazırlanan ve konu anlatımı yapılan okuma stratejini uygulamaya yönelik etkinlikler de iki günlük aranın ardından Dersler sayfasında paylaşılmıştır. Fazladan okuma, dinleme ve izleme etkinlikleri yapmak isteyen öğrenciler için haberin konusuyla ilgili internet bağlantı adresleri, sınıf dışı etkileşimi artırmak amacıyla konuyla ilgili bir tartışma bölümü ve tasarım geliştirme anketi de bu bölümde yer almaktadır. Ders dışı okumayı teşvik etmek amacıyla, öğrencilerin ilgisini çekebilecek haber metinleri Bunları Biliyor musunuz? sayfasında, görsel ve işitsel algıyı harekete geçirerek anlamayı kolaylaştırmak ve öğrenmeyi keyifli kılmak adına, Türk Edebiyatından seslendirilmiş kısa öyküler de Sesli Kütüphane bölümünde haftanın beşinci ve altıncı günleri paylaşılmıştır. Yabancılara Türkçe öğretimi üzerine hazırlanmış bilgisayar ve akıllı telefon uygulamaları ise yedinci bölüm olan Mağaza sayfasına eklenmiştir. Uygulama sonunda, öğrenciler ve öğretim elemanlarıyla yarı yapılandırılmış yüz yüze görüşmeler gerçekleştirilerek çalışmanın nitel verileri elde edilmiştir. Uygulama süreci Tablo 1'te gösterilmiştir.

SEFAD, 2018 (39): 251-266 
Tablo 1: Uygulama Süreci

\begin{tabular}{|c|c|c|}
\hline Grup & Uygulama & $\begin{array}{c}\text { Veri Toplama } \\
\text { Araçları } \\
\end{array}$ \\
\hline \multicolumn{3}{|c|}{ Sınıf içi mevcut müfredat takibi } \\
\hline & + & Öğrenci \\
\hline OGÜ & Sınıf dişı blog uygulaması x 6 hafta & Görüşmeleri \\
\hline TÖMER & - Okuma stratejileri konu anlatımı & + \\
\hline \multirow[t]{4}{*}{ B2 Düzeyi } & - Gazete haber metinleri & Öğretmen \\
\hline & - Tartışma bölümü & Görüşmeleri \\
\hline & - Konuyla ilgili bağlantı adresleri & \\
\hline & - Tasarım geliştirme anketi & \\
\hline
\end{tabular}

Öğrenciler ve öğretim elemanlarıyla gerçekleştirilen görüşmelere ait ses kayıtları yazıya aktarılarak elde edilen veriler araştırmacı tarafından betimsel analiz yöntemleri ile çözümlenmiştir.

\section{BULGULAR}

Türkçenin yabancı dil olarak öğretiminde blog kullanımına yönelik öğrenci ve öğretmen görüşlerinin araştırıldığı bu nitel çalışmanın verileri, araştırmacı tarafından özgün olarak hazırlanmış öğrenci ve öğretim elemanı görüşme formlarından elde edilmiştir. Öncelikle, yarı yapılandırılmış görüşmelere ait ses kayıtları yazıya aktarılarak elde edilen veriler araştırmacı tarafından betimsel analiz yöntemleri ile incelenmiştir.

Görüşmelerde, Türkçe öğrenme amaçlarının sorulduğu ilk soru için öğrenciler, “Türkiye'de eğitim almak, sosyal çevre edinmek ve öz yeterliklerini artırmak " gibi ortak cevaplar vermişlerdir. (Bk. Tablo 2).

Tablo 2: Katılımcıların Türkçeyi öğrenme amaçları

\begin{tabular}{ccc}
\hline Ana Tema & Alt Temalar & Görüş Sıklığı (Öğrenci) \\
\hline & Eğitim & 7 \\
\cline { 2 - 3 } Türkçe Öğrenme Amaçları & Sosyal çevre & 5 \\
\cline { 2 - 3 } & Özyeterlik & 4 \\
\cline { 2 - 3 } & Kültür & 2 \\
\cline { 2 - 3 } & İş & 2 \\
\hline
\end{tabular}

İkinci soruda yabancı dil öğrenmede blogların avantajları ve dezavantajları sorulduğunda, öğrenciler blogların yeni, eğlenceli ve teknolojik özellikleri sayesinde ilgi çekici öğrenme ortamları olduğunu ifade etmişlerdir. Biri yüksek lisans eğitimine Türkçe Öğretimi alanında devam eden ve beş yıldır yabancılara Türkçe öğreten, diğeri doktora eğitimine Yabancı Dil Olarak Türkçe Öğretimi alanında devam eden ve altı yıldır yabancılara Türkçe öğreten öğretim elemanlarına da aynı soru sorulmuş ve benzer cevaplar alınmıştır (Bk. Tablo 3). 
Tablo 3: Yabancı Dil Öğrenmede Blog Desteğinin Avantajları/Dezavantajları

\begin{tabular}{|c|c|c|}
\hline Ana Tema & Alt Temalar & Görüş Sıklığı (Öğrenci) \\
\hline \multirow{4}{*}{ Avantajlar } & Eğlenceli & 7 \\
\hline & Yeni & 5 \\
\hline & İlgi çekici & 5 \\
\hline & Teknolojik & 4 \\
\hline \multirow{2}{*}{ Dezavantajlar } & Internet bağlantısı & 2 \\
\hline & Şarj & 1 \\
\hline
\end{tabular}

Buna ek olarak, ders dışında öğrenci ve ödev takibini kolaylaştırması, etkileşimli öğrenme ortamları ve öğrencilere geri bildirim imkânı sunması, blogların öğretmelere sağladığı avantajlar konusunda öğretim elemanlarının görüşleridir. Daha önce kişisel ya da eğitim amaçlı blog kullanmadıklarını belirten öğretim elemanları, internet kesintisi, cihaz edinimi ve şarj sorunu gibi, öğrencilerin de değindiği sorunların blogların dezavantajları olduğundan söz etmişlerdir.

Blogda yapılması istenen değişiklikler ve eklemelerle ilgili olarak görüşleri sorulduğunda öğrenciler blog uygulaması ile ilgili olarak herhangi bir değişiklik yapılmasını önermezken, öğretim elemanları blog uygulamasının B2 düzeyinin yanında diğer beceri düzeylerini de kapsayacak şekilde geliştirilmesini önermişlerdir. Bloğa yapılması düşünülen eklemelerle ilgili olarak öğrenciler basamaklı öyküler, metin içi sözlük uygulaması, konu anlatım videoları ve oyun uygulamalarının eklenmesini önerirken, öğretim elemanları öğretmenlerin bloglar konusunda eğitim almalarını ve blog uygulamasının müfredat kapsamına alınmasını önermişlerdir (Bk. Tablo 4).

Tablo 4: Blogda Yapılması İstenen Eklemeler/Değişiklikler

\begin{tabular}{ccc}
\hline Ana Tema & Alt Temalar & Görüş Sıklı̆̆ı (Öğrenci) \\
\hline \multirow{2}{*}{$\begin{array}{c}\text { Değişiklikler } \\
\&\end{array}$} & Basamaklı öyküler & 2 \\
\cline { 2 - 3 } Eklemeler & Metin içi sözlük & 2 \\
\cline { 2 - 3 } & Video & 2 \\
\hline
\end{tabular}

Öğrenciler, geleneksel öğrenmeyle karşılaştırdıklarında, blog uygulamasının daha güncel ve ilgi çekici konulara sahip olması bakımından öğrenme sürecine katılımı artırdığ ve öğrenmeyi keyifli bir deneyime dönüştürdüğünü ifade etmişlerdir (Bk. Tablo 5). 
Tablo 5: Geleneksel Öğrenme ile Blogla Öğrenme Arasındaki Farklar

\begin{tabular}{ccc}
\hline Ana Tema & Alt Temalar & Görüş Sıklığı (Öğrenci) \\
\hline \multirow{3}{*}{$\begin{array}{c}\text { Geleneksel Öğrenme } \\
\&\end{array}$} & İlgi çekici konular & 6 \\
\cline { 2 - 3 } Blogla Öğrenme & Derse katılım & 4 \\
\cline { 2 - 3 } & Ĕğlenerek öğrenme & 2 \\
\cline { 2 - 3 } & Bağımsız mekân/zaman & 2 \\
\hline
\end{tabular}

Blog içeriğiyle ilgili olarak, okuma stratejilerinin öğrenimini amaçlayan konu anlatımı ve etkinlikleri ile güncel haber metinleri ve sesli öykülerin en çok beğendikleri etkinlikler olduğunu belirtmişlerdir (Bk. Tablo 6).

Tablo 6: Beğenilen \& Beğenilmeyen Blog Etkinlikleri

\begin{tabular}{ccc}
\hline Ana Tema & Alt Temalar & Görüş Sıklığı (Öğrenci) \\
\hline \multirow{3}{*}{ Beğenilen } & Dersler & 4 \\
\cline { 2 - 3 } & Konu anlatımı & 3 \\
\cline { 2 - 3 } & Bunları biliyor muydunuz? & 2 \\
\cline { 2 - 3 } & Sesli öyküler & 2 \\
\hline Beğenilmeyen & - & - \\
\hline
\end{tabular}

Blog uygulamasının okuma başarısına etkisi bağlamında, okuma teknikleri öğretiminin okuma hızını ve okuduğunu anlama başarısını artıran bir etken olduğu öğrencilerin ve öğretim elemanlarının ortak düşünceleridir.

Tablo 7: Blog Etkinliklerinin Okuma Başarısına Etkisi

\begin{tabular}{ccc}
\hline Ana Tema & Alt Temalar & Görüş Sıklığı (Öğrenci) \\
\hline & Okuma teknikleri & 7 \\
\cline { 2 - 3 } Okuma Başarısı & Okuma hızı & 4 \\
\cline { 2 - 3 } & Sözcük bilgisi & 1 \\
\hline
\end{tabular}

Blogda paylaşılan haber metinlerinin, dilin özgün kullanımına örnekler sunarak öğrencileri okumaya teşvik ettiğini ve okuma sıklığı arttıkça özgüvenin de buna bağlı olarak arttı̆̆ını ifade eden öğretim elemanları, blog uygulamasının sadece okuma becerisini değil genel akademik başarıyı ve motivasyonu da artıran bir öğrenme biçimi olduğunu belirtmişlerdir. İleride, kendi derslerinde blog kullanımı ile ilgili düşünceleri sorulduğunda, her iki öğretim elemanı da bloglar konusunda gerekli eğitimi aldıktan sonra kişisel blog sitelerini kurmak istediklerini ve temel dil becerilerini kapsayacak şekilde blogları derslerinde kullanmak istediklerini belirtmişlerdir. 


\section{SONUÇ VE ÖNERİLER}

İlgi alanları ve ihtiyaçları bağlamında, önceki kuşaklara göre profili bir hayli farklılaşan bugünün öğrencilerini başarıya yönlendirmede atılacak en önemli adımlardan birisi, hiç şüphe yok ki onların öğrenmeye karşı olumlu tutum geliştirmelerini sağlamaktır. $\mathrm{Bu} \mathrm{da}$, öğrenme ortamlarının ve kullanılacak olan öğretim malzemelerinin öğrencilerin ilgi ve ihtiyaçlarına uygun olmasıyla yakından ilgilidir. Geleneksel öğretim yöntemlerinin dijital yerlilerin yabancı dil öğrenme ihtiyaçlarını karşılamada yetersiz oluşu, gerek sınıf içinde gerek sınıf dışında, teknoloji de işe koşularak, iletişimsel ve etkileşimli öğrenme ortamlarının geliştirilmesi gereğini doğurmaktadır. Bu anlayışla, günümüz eğitim sisteminin dinamikleri ve dijital neslin özellikleri göz önünde bulundurularak, sınıf dışında ihtiyaç duyulan etkileşimli dil öğrenme ortamlarının Web 2.0 araçlarından biri olan bloglar aracılığıyla sağlanacağ 1 düşünülmektedir.

Blogların yabancı dil olarak Türkçe öğretiminde kullanımına ilişkin öğrenci ve öğretmen görüşlerinin araştırıldığı bu çalışmanın sonucu, kullanımı kolay ve eğlenceli araçlar olan blogların etkili ve etkileşimli öğrenme ortamları sunan ve öğrencilerin öğrenmeye karşı tutumlarını olumlu yönde etkileyen araçlar olduğu yönündedir. Teknolojik özellikleri sayesinde dijital yerlilerin ilgisini çekmeyi başaran bloglar okul sınırlarını aşarak, dijital yaşamın sınırları içerisinde öğrenmeyi keyifli bir etkinliğe dönüştürmüştür.

Öğrenciler ve öğretim elemanlarıyla yapılan görüşmelerden, blogların yabancı dil öğrenenler için yeni ve ilgi çekici bir öğrenme biçimi olduğu ve ders dışı etkileşimi artırarak öğrenmeyi desteklediği anlaşılmıştır. Bu sebeple, B2 düzeyinde Türkçe öğrenenler için tasarlanan blog uygulamasının içerik ve yöntem açısından diğer beceri düzeylerini de kapsayacak şeklide geliştirilmesi yönünde ulaşılan sonuçlar yeni çalışmalara ihtiyaç duyulduğunu göstermektedir. Tasarım tabanlı yürütülecek bir araştırma ile blogların yabancı dil olarak Türkçe öğretimine etkisi tüm düzeylerde araştırılarak, her düzeyde öğrencilerin ihtiyaçlarına uygun blog tabanlı öğretim malzemeleri ve uygulama yöntemleri geliştirilmelidir.

Bireysel farklılıkları öne çıkaran sonuçlara göre, basamaklı öykülerin bloğa eklenmesi öğrencilerin kendi okuma düzeylerine uygun kitapları seçmelerini sağlayacaktır. Benzer şekilde bloğa videolar eklenmesi, farklı öğrenme stillerine sahip öğrencilerin kendi ilgi alanları ve ihtiyaçlarına uygun öğretim malzemeleri ve etkinlikleri arasından tercih yapmalarına olanak sağlayacaktır.

Öğrencilerin, blogla ilgili düşüncelerini ifade ederken genellikle akıllı telefonları dikkate alarak değerlendirmeler yapmaları çalışmanın dikkat çekici sonuçları arasındadır. Buna göre, akıllı telefonların ekran boyutu ve kullanım özellikleri göz önüne alındığında, sayfalar arası geçiş yapmak dikkat dağıtacağından metin içi sözlük uygulamasının dikkate değer bir öneri olduğunu söylemek mümkündür. Bir yazılım programı geliştirilerek akıllı telefonlarda sözlük kullanımı kolaylaştırılmalıdır.

Çalışmanın öne çıkan bir diğer sonucu, geleneksel öğrenmeye kıyasla konuların daha ilginç ve güncel olmasının öğrenmeye olan ilgiyi ve derse katılımı artıran önemli bir etken olduğu yönündeki öğrenci ve öğretim elemanlarının ortak görüşleridir. Öğretim elemanlarıyla yapılan görüşmelerde, yabancı dil becerilerini geliştirmenin yanı sıra blogların genel akademik başarıyı ve motivasyonu da artıran bir öğrenme biçimi olduğu, bu sebeple blog uygulamasının müfredat kapsamına alınarak derslere dâhil edilmesi gerektiği yönünde sonuçlara ulaşılmıştır. Bu bağlamda, bir ders dışı öğrenme ortamı olarak tasarlanan bloglar, sınıf içi öğrenmeyi destekleyecek şekilde tasarlanarak benzer bir yöntemle yeniden 
uygulanmalıdır. İleride yapılacak böyle bir çalı̧̧mayla, blogların sınıf içi ya da sınıf dışı ortamlarda yabancı dil olarak Türkçe öğretimine etkisi araştırılarak ihtiyaca uygun kullanım yöntemleri belirlenmelidir.

\section{SUMMARY}

As it promotes communication and interaction, the use of Web 2.0 tools has gradually increased in modern education system where technological capability is discussed as one of the basic language skills. This study has been conducted to investigate the effects of blogs, which is a type of Web 2.0 tools, on teaching Turkish as a foreign language, when designed as an out-of-class learning environment. In the light of the principles of blended learning, a blog page was created by the researcher and the material was implemented to the students as an out-of-class teaching material.

The participants were 24 university students learning Turkish as a foreign language in B2 proficiency level. In order to investigate the effects of blog use on teaching Turkish as a foreign language, semi-structured interviews were held with seven students and two instructors who were randomly selected after the implementation process, and they were asked to evaluate the scope and method of the study, activity types and the content and technical features of the blog site.

Design based research method was applied in this study, and newspaper articles were used in order to design the blog content. At the very beginning, the students were asked to find out their routines for following the news and this had a big impact on deciding the content and implementation process. Throughout the six-week-study, it was aimed to teach the reading strategies, which were determined according to B2 level outcomes in CEFR, and reading activities were prepared and applied accordingly. To this end, current news were selected from newspapers and reading comprehension questions were prepared. Besides, a discussion part was added to the blog in order to facilitate interaction among students outside the class and enhance learning by encouraging them to comment on each other. At the end of the study; a blog based teaching material was designed according to the students' needs and interests.

The results of the study revealed that blog based learning model improves motivation for learning by preparing an enjoyable and interactive learning environment. In addition, the results indicated that blogs, compared with traditional learning methods, have up-to-date and interesting content and therefore increase participation and communication among students. These findings suggest the need for further research on developing blog content considering other proficiency levels and exploring the implementation of blogs in class environments. 


\section{KAYNAKÇA}

Ahmad, Khurshid-Corbett, Greville vd. (1985). Computers, Language Learning, and Language Teaching. Cambridge: Cambridge University Press.

Al-Qallaf-Charlene L.-Al-Mutairi, Afaf S.R. (2016). "Digital Literacy and Digital Content Supports Learning: The Impact of Blogs on Teaching English as a Foreign Language". The Electronic Library 34(3): 522-547.

Altun, Mustafa (2015). "The Integration of Technology into Foreign Language Teaching". International Journal on New Trends in Education and Their Implications 6(1): 22-27.

Aydan, L. Seda (2014). Student and Teacher Perceptions on Benefits and Challenges of Using Blogs in English in Foreign Language Reading Classes. Yüksek Lisans Tezi. Ankara: Orta Doğu Teknik Üniversitesi.

Baron, Naomi S. (2008). Always on: Language in an Online and Mobile World. Oxford: Oxford University Press.

Bates, Tony (2011). "Undestanding Web 2.0 and Its Implications for E-Learning". Web 2.0Based E-learning: Applying Social Informatics for Tertiary Teaching. ed. Mark J. W. LeeCatherine McLoughlin. Hershey Pa.: Information Science Reference. 21-42.

Blackstone, Brad-Spiri, John vd. (2007). "Blogs in English Language Teaching and Learning: Pedagogical Uses and Student Responses". Reflections on English Language Teaching 6(2): 1-20.

Bush, Michael D. (1997). "Implementing Technology for Language Learning". TechnologyEnhanced Language Learning. ed. Michael D. Bush-Robert M. Terry. Lincolnwood, III: National Textbook in conjunction with the American Council on the Teaching of Foreign Languages. 287-349.

Demirel, Özcan (1987). Yabancı Dil Öğretimi: Illkeler, Yöntemler, Teknikler. Ankara: USEM Yay.

Demirel, Özcan (2009). Öğretim Illke ve Yöntemleri: Öğretme Sanatı. Ankara: PeGem A Yay.

Egbert, Joy (2005). Call Essentials: Principles and Practice in Call Classrooms. Alexandria, Virginia: Teachers of English to Speakers of Other Languages.

Hope, Geoffrey R.-Taylor, Heimy F. vd. (1984). Using Computers in Teaching Foreign Languages. Englewood Cliffs, N.J: Prentice-Hall Regents.

Izquierdo, Bertha Leiva de-Reyes, Leticia Esteves (2009). "Effectiveness of Blogging to Practice Reading at a Freshman EFL Program". The Reading Matrix 9(2): 100-117.

Ilter, Binnur G. (2009). "Effect of Technology on Motivation in EFL Classrooms". Turkish Online Journal of Distance Education-TOJDE 10(4): 136-158.

Kartal, Bilhan (2001). Açıköğretim Öğrencilerinin Yabancı Dil Derslerinde Teknoloji Kullanımına İlişkin Görüşleri. Eskişehir: Anadolu Üniversitesi Yay.

Kern, Richard-Warschauer, Mark (2000). "Theory and Practice of Network-Based Language Teaching". Network-Based Language Teaching: Concepts and Practice. ed. Richard KernMark Warschauer. Cambridge: Cambridge University Press. 1-19.

Larsen-Freeman, Diane (2000). Technques and Principels in Language Teaching. Oxford: Oxford University Press.

Mondahl, Margrethe-Razmerita, Liana (2014). "Social Media, Collaboration and Social Learning-A Case-study of Foreign Language Learning". The Electronic Journal of eLearning 12(4): 339-352. https://eric.ed.gov/?id=EJ1035665 [13 Kasım 2016]

Nicolaou, Anna-Constantinou, Elis K. (2014). "Blogging Revisited: The Use of Blogs in ESAP Courses". International Conference on Learning and Collaboration Technologies (haz.

SEFAD, 2018 (39): 251-266 
Panayiotis Zaphiris-Andri Ioannoupp). 22-27 Haziran 2014. Cham: Springer International Pub. 95-106.

https://link.springer.com/chapter/10.1007/978-3-319-07482-5_10 [03 Ocak 2017]

Noytim, Usa (2010). "Weblogs Enhancing EFL Students' English Language Learning". Procedia - Social and Behavioral Sciences 2(2): 1127-1132.

Odabaşı, H. Ferhan (1997). Yabancı Dil Eğitiminde Bilgisayar Kullanımı. Eskişehir: Anadolu Üniversitesi Yay.

Rashtchi, Mojgan-Hajihassani, Hassan (2010). "Blog-Assisted Language Learning: A Possibility in Teaching Reading to Iranian EFL Learners". International Journal of Language Studies (IJLS) 4(4): 245-262.

Šabanović, Izela Habul (2015). "Using Blogs To Promote Student Interaction and Learning in EFL Classes". Journal of Transdisciplinary Studies 8(2): 9-22.

Sarıçoban, Arif (2006). Instructional technologies and Material Design for Foreign Language Teaching. Ankara: Anı Yay.

Schwienhorst, Klaus (2008). Learner Autonomy and CALL Environments. New York: Routledge/Taylor \& Francis Group.

Sharma, Pete-Barrett, Barney (2007). Blended Learning: Using Technology in and beyond the Language Classroom. Oxford: Macmillan.

Solomon, Gwen-Schrum, Lynne (2010). Web 2.0: How to for Educators. Eugene, Oregon: International Society for Technology in Education.

Sydorenko, Tatyana-Myers, Tom vd. (2008). "Pedagogical Uses of Multimedia Annotators and Players". Technology Enhanced Learning: Best Practices. ed. Miltiadis D. LytrasDragan Gaseviç vd. Hershey, New York: IGI Pub. 185-204.

Szendeffy, John de (2005). A Practical Guide to Using Computers in Language Teaching. Ann Arbor, USA: University of Michigan Press.

Şahan, H. Hüseyin (2007). "İnternet Tabanlı Öğretim". Eğitimde Yeni Yönelimler. ed. Özcan Demirel. Ankara Pegem A Yay. 233-244.

Telc (2013). Avrupa Konseyi, Modern Diller Bölümü. Diller İçin Avrupa Ortak Öneriler Çerçevesi Öğrenim, Öğretim ve Değerlendirme. (İkinci Baskı) Almanya: Telc GmbH.

https://www.telc.net/fileadmin/user_upload/Publikationen/Diller_iain_Avrupa_Ortak_oneri ler_AEeraevesi.pdf [03 Haziran 2016]

Temir, Tuğçe (2015). Relationship between Using Blogs and Achievement in Reading Skills of PrepClass Students at Tertiary Level. Yüksek Lisans Tezi. Ankara: Hacettepe Üniversitesi.

Ward, Jason M. (2004 ). "Blog Assisted Language Learning (BALL): Push Button Publishing for the Pupils". TEFL Web Journal 3(1): 1-16. http://www.espworld.info/Articles_26/push\%20button\%20publishing\%20ward\%202004.pdf [23 Ekim 2016]

White, Cynthia (2003). Language Learning in Distance Education. Cambridge: Cambridge University Press.

Yüksel, Okan (2014). İnternet Gazeteciliği ve Blog Yazarlı̆̆ı. Ankara: Sinemis Yay.

Zarei, Nafiseh-Al-Shboul, Yasser (2013). "Participating in a Blog: Jordanian EFL Learners' Voices". English Linguistics Research 2(2): 52-59.

Zeqiri, Luiza (2013). "The Impact of Integrating Weblogs into an ESP Classroom". South East European University Review 9(1): 46-62. https://www.degruyter.com/downloadpdf/j/seeur.2013.9.issue-1/seeur-2013-0005/seeur2013-0005.pdf [02 Aralık 2016] 